\title{
Concepções teóricas de docentes do ensino fundamental acerca do processo de ensino e aprendizagem de leitura
}

\author{
Sabatha Catoia Dias \\ Universidade Federal de Santa Catarina
}

\begin{abstract}
Resumo
Este estudo tem como tema leitura, entendida como coconstrução de sentidos. O objetivo é descrever analiticamente concepções docentes sobre as práticas de leitura nas aulas de Língua Portuguesa, fazendo-o com foco no domín io teórico-epistemológico. Assim, pretende-se responder à seguinte questão: Em se tratando de como professores de Português dos anos finais do Ensino Fundamental de escolas estaduais de Florianópolis/SC informam trabalhar com leitura - com foco em sua ancoragem teórica -, é possível depreender fundamentos do ideário histórico-cultural? Para responder à questão, analisam-se respostas obtidas por meio de entrevistas. $\mathrm{O}$ aporte teórico constitui-se de estudos de gêneros discursivos de Bakhtin (2010 [1952/53]) e de teorias de letramento, com base no pensamento de Street (1984, 1988, 2003), entre outros. A análise dos dados depreende concepções docentes ainda difusas emergindo como ecos do ideário histórico-cultural. Assim, a contribuição deste estudo reside no desvelamento da necessidade de ressignificações acadêmicas nas formações docentes, considerando o compromisso da universidade com a excelência da ação pedagógica na escola pública.

Palavras-chave: Ensino e aprendizagem de leitura/práticas de leitura; professores de Língua Portuguesa do Ensino Fundamental; concepções docentes; ideário histórico-cultural.
\end{abstract}

\begin{abstract}
The subject of this study is reading understood as co-construction of meanings. The objective is to draw an analytical description of teacher conceptions about the reading practices in Portuguese language classes, focusing on theoretical-epistemological domain. Therefore, this article aims to answer the following question: "How do Portuguese language teachers, who teach the final years of elementary education in state schools, in Florianópolis, Santa Catarina, report working with reading in class, from a theoretical focus, and is it possible to deduce the founding principles of the cultural-historical ideology from their reports?" To answer this question, replies obtained in interviews are analyzed. The bases that guided this study are Bakhtin's studies of discursive genres (2010 [1952/53]) and literacy theories, based on Street $(1984,1988,2003)$ and others. The data analysis shows that teacher conceptions are still diffused, emerging as echoes of the cultural-historical ideology. The contribution of this study is to reveal the
\end{abstract}


need for academic resignifications in teachers' development, considering the university's commitment to the excellence of pedagogical actions in public schools.

Keywords : Teaching and learning of reading/ reading practices; Elementary School Portuguese Language teachers; teacher conceptions; culturalhistorical ideology.

\section{INTRODUÇÃO}

A leitura constitui uma atividade necessária no contexto em que estamos inseridos, uma vez que diversas interações humanas são instituídas por meio de textos escritos. Nesse contexto, crescentemente mais grafocêntrico (FISHER, 2006), faz-se imprescindível a condição de leitores proficientes por parte dos sujeitos a fim de se inserirem e se moverem socialmente, bem como promoverem transformações sociais.

A escola - compreendida atualmente como a principal agência de letramento - e, especificamente, as aulas de Língua Portuguesa têm de implementar nos alunos habilidades nas práticas de linguagem nas modalidades oral e escrita da língua, facultando-lhes a participação ativa na vida em sociedade.

Parece, contudo, que tem se tornado pública a crítica referente à inoperância escolar no ensino e na aprendizagem de língua materna nas escolas brasileiras em vista de dados publicados por diversos indicadores, tais como o INAF (2009) e o PISA (2009). Afirma-se que muitos estudantes da Educação Básica em nosso país não têm desenvolvidas habilidades básicas de uso da língua em se tratando de práticas como leitura e escrita em textos pertencentes a gêneros discursivos secundários, não conseguindo se expressar clara e objetivamente.

Entendemos que a leitura é uma atividade humana de coconstrução de sentidos que ocorre dentro e fora da escola; porém, a nosso ver, é no âmbito da instituição de ensino, particularmente nas aulas de Português, que são desenvolvidas e aprimoradas habilidades concernentes ao ato de ler; ou seja, é função do professor de língua materna trabalhar a leitura abordando suas especificidades, tal qual propõe Geraldi (1997 [1991]).

Em nosso entendimento, toda prática pedagógica é desenvolvida de acordo com as concepções que os docentes sustentam e que divergem segundo suas formações profissionais. Assim, o ensino e a aprendizagem de leitura empreendidos nas escolas brasileiras parecem estar intimamente relacionados às concepções que professores de Língua Portuguesa mantêm acerca dessa atividade e de suas práticas em sala de aula. 
Diante desse quadro e do entendimento que temos acerca da relação intrínseca entre teoria e prática, surge o seguinte questionamento: Em se tratando de como professores de Português dos anos finais do Ensino Fundamental de escolas estaduais de Florianópolis/SC informam trabalhar com leitura - com foco e m sua ancoragem teórica -, é possível depreender fundamentos do ideário históricocultural, nos contornos com que esse ideário tem se estabelecido nas discussões teóricas e nos docume ntos oficiais no Brasil?

O presente artigo constitui recorte de pesquisa (CATOIA DIAS, 2012) e seu enfoque é leitura - mais especificamente, as práticas de leitura de textos escritos na escola - e tem como objetivo descrever analiticamente concepções docentes sobre tais práticas nas aulas de Língua Portuguesa, em escolas estaduais que atendam aos sétimo, oitavo e nono anos do Ensino Fundamental no município de Florianópolis/SC, depreendendo reverberações do ideário histórico-cultural ${ }^{1}$ nessas concepções. Tal enfoque é tomado sob o ponto de vista teórico-epistemológico, no que diz respeito às teorias bakhtinianas sobre gêneros do discurso e ao ideário do letramento.

\section{FUNDAMENTAÇÃO TEÓRICA: A LEITURA À LUZ DO IDEÁRIO HISTÓRICO-CULTURAL}

Nesta seção explicitaremos as bases teóricas que fundamentam o presente estudo: os ideários do Círculo de Bakhtin acerca de gêneros discursivos (2010 [1952/53]), e as teorias sobre letramento, com base sobremodo no pensamento de Street (1984, 1988, 2000, 2003, 2010), Hamilton (2000), e Barton(1994).

\section{O olhar do Círculo de Bakhtin}

Nos últimos anos, muitas pesquisas na área da Linguística Aplicada têm se ancorado nos postulados bakhtinianos, considerando que tais estudos tratam da linguagem em uma abordagem histórico-cultural, especificamente sob uma concepção dialógica. O dialogismo, tema central na discussão do ideário do Círculo de Bakhtin,

\footnotetext{
${ }^{1}$ Por ideário histórico-cultural, estamos entendendo construtos teóricos que concebem a língua como instrumento psicológico de mediação simbólica, por meio da qual se instituem relações interpessoais situadas sociocultural e historicamente, o que nos leva ao pensamento de autores como L. Vigotski e M. Bakhtin e seus seguidores. Entendemos mais apropriado usar a expressão histórico-cultural e não sociointeracionista porque compreendemos que tais interações - necessariamente sociais sob essa perspectiva (diferentemente da perspectiva piagetiana) - só se estabelecem no plano da história e da cultura.
} 
caracteriza-se como uma filosofia (FARACO, 2007), como aspecto fundante da essência humana. O termo diálogo "[...] é o nome para o simpósio universal que define o existir humano" (FARACO, 2007, p. 44).

Os estudos bakhtinianos sobre linguagem perpassam caminhos relativos à história, à interação, à existência etc., desdobramentos profundamente imbricados com os modos como utilizamos a língua e como nos constituímos e nos modificamos nas relações com o outro mediadas por ela. Nessa perspectiva, a historicidade do sujeito e da língua é de crucial importância para as representações que se fazem do existir humano e de sua constituição, via linguagem, nas diferentes interações sociais.

Fundamental apontar que tratar de interações humanas é, indubitavelmente, tratar de valorações, uma vez que viver é se posicionar a cada instante frente a diferentes valores. Assim, a filosofia bakhtiniana constitui uma axiologia, "uma teorização primeira sobre valores" (FARACO, 2007, p. 45). Nesse ideário, é no jogo axiológico que os sujeitos vão se constituindo e tal constituição só ocorre devido à existência do outro, da alteridade, por meio da linguagem que, por sua vez, se dá via enunciados e, por implicação, via gêneros discursivos.

Lingua(gem) em uma abordagem histórico-cultural

Língua, no ideário histórico-cultural, é concebida como interação. De acordo com estudos bakhtinianos, a realidade da língua é social, sendo assinalada por uma dimensão sócio-histórica que a constitui e que funciona como seu cerne. A língua só existe de fato nas interações por meio de enunciações materializadas entre os sujeitos. Importa apontar que Bakhtin [Volochinov] (2009 [1929]) não nega a existência de um sistema linguístico, contudo considera equivocado entender a língua, em sua totalidade, como um sistema imanente, tal qual é concebida pelo objetivismo abstrato.

$\mathrm{Na}$ visão bakhtiniana, reduzir a língua a um sistema de normas transmissíveis é abstraí-la de seu dinamismo natural, é freá-la e destituí-la daquilo que melhor a representa: sua natureza interacional. Conforme aponta Bakhtin [Volochinov] (2009 [1929], p. 95), “A consciência subjetiva do locutor não se utiliza da língua como de um sistema de formas normativas. [...] O sistema linguístico é o produto de uma reflexão sobre a língua, reflexão que não procede da consciência do locutor [...] e que não serve aos propósitos imediatos da comunicação [...]", ou seja, o sujeito não compreende a língua como códigos a serem codificados e decodificados, ao contrário, ele se serve da 
língua para satisfazer seus interesses enunciativos visando sempre à reação resposta de seu interlocutor.

Outra escola de pensamento também criticada pelo Círculo de Bakhtin é a do subjetivismo individualista, pois essa abordagem toma como ponto de partida do estudo linguístico a enunciação monológica. Sob essa ótica, é o interior que organiza toda enunciação e toda expressão, ou seja, des vincula-se a enunciação de sua natureza social. Contrapondo-se a esse entendimento, Bakhtin [Volochinov] (2009 [1929]) afirma que a língua vive na comunicação verbale não no psiquismo individual dos sujeitos.

Entender a língua em sua realidade concreta é, portanto, concebê-la como interação, como discurso. É perceber sua dinamicidade determinada, sobretudo, pelos usos sociais a que está sujeita. É compreender que ela nasce, constitui-se e se modifica nas interações pelas quais passam sujeitos sócio-historicamente situados, ou seja, o discurso se origina no diálogo, na confluência de diversas vozes sociais via gêneros discursivos, dos quais trataremos na seção seguinte.

\section{Os enunciados e os gêneros discursivos}

Segundo Bakhtin, a materialização do discurso se dá na forma de enunciados, que se caracterizam como a unidade real das interações, podendo ser orais ou escritos, e que se apresentam intimamente relacionados com enunciados anteriores, bem como com enunciados posteriores, configurando, dessa forma, elos na cadeia da comunicação discursiva (BAKHTIN, 2010 [1952/53]).

Conforme explica o autor, todo enunciado “[...] é pleno de palavras dos outros [...]. Essas palavras dos outros trazem consigo a sua expressão, o seu tom valorativo que assimilamos, reelaboramos, e reacentuamos" (BAKHTIN, (2010 [1952/53], p. 296297).

Rodrigues (2005) afirma que o enunciado (assim como o gênero discursivo) é composto por duas dimensões: a) dimensão linguística: verbal, com uma expressão semiótica materializada; e b) dimensão social: extraverbal, a situação social em que se profere o discurso. Essa segunda dimensão, denominada por Bakhtin de "situação social mais imediata", é que determina a cons trução do enunciado.

Nessa abordagem, o sujeito é entendido como agente responsivo ativo. Ao interagir, ele se modifica, modifica o outro, o mundo e a própria língua. Como aponta Faraco (2007), cada ser humano - que é único - é ao mesmo tempo efeito da alteridade. 
O outro, na atividade linguística, cumpre o papel de coconstrutor dos sentidos e da constituição de seu interlocutor. Os sujeitos, sob tal perspectiva, não são assujeitados nem determinados pelo entorno cultural; pelo contrário, eles transformam a si e ao meio em que se encontram.

O próprio enunciador, em uma situação interativa, espera a posição responsiva ativa de seu interlocutor, vis to que ele aguarda uma participação. Ele, como enunciador, também é um "respondente ativo" de outros enunciados que precederam o seu e que, inquestionavelmente, constituem o seu discurso. Eis os elos da comunicação discursiva.

Nessas relações, a conclusibilidade dos enunciados ocorre por meio da alternância dos sujeitos do discurso, ou seja, um enunciado tem seu término marcado como início dos enunciados responsivos do outro.

Vale registrar que o sujeito que enuncia procura antecipar o seu enunciado de forma que as objeções que possam surgir nas respostas de seus interlocutores sejam previstas e respondidas. Como todo discurso é dirigido a um interlocutor, a existência do outro orienta a produção do discurso. O conhecimento que o autor tem do(s) outro(s) que constitui(em) seu auditório social o instrui para que se posicione perante ele (auditório social) de maneira a instigá-lo, no intuito de que o outro responda ativamente a seu enunciado.

O enunciado serve, portanto, como ponto de partida para a construção de sentido, para a interação. A interação verbal, a propósito, é um dos elementos axiais da teoria de Bakhtin, uma vez que, segundo o autor, é nas interações que os sujeitos entram em contato uns com os outros, relacionam-se, socializam e historicizam experiências e valores e, assim, influenciam-se, modificando a si mesmos e ao outro.

Essas interações, constituídas pelos sujeitos e, ao mesmo tempo, constituintes deles, configuram-se em e se instituem por diferentes usos da língua em gêneros do discurso diversos que se materializam em forma de enunciados. Os gêneros são, dessa forma, representantes das diversas esferas da atividade humana.

Os gêneros discursivos funcionam como instituidores das relações humanas e o fazem por meio de enunciados. Os enunciados não existem senão dentro de diferentes gêneros discursivos que são, segundo o autor, "tipos relativamente estáveis de enunciados", elaborados por cada campo de utilização da língua (BAKHTIN, 2010 [1952/53], p. 262, grifos do autor).

Com relação à relativa estabilidade dos gêneros, implica reconhecer que eles se adaptam às mudanças sociais, modificando-se com o desaparecimento de algumas 
interações e com o surgimento de outras novas. Bakhtin (2010 [1952/53]) explica que a diversidade de gêneros é enorme, uma vez que são inúmeras as possibilidades da multiforme atividade humana. Assim, os gêneros se originam, desenvolvem-se e se diferenciam à medida que se dá o desenvolvimento e a complexificação de um determinado campo.

Nesta abordagem, os gêneros se dividem em gêneros primários e gêneros secundários; ambos apresentam uma dimensão estilística, uma temática e outra composicional. Os gêneros discursivos primários são aqueles que estão mais relacionados à oralidade e às interações caracterizadas por uma complexidade menor que aquela presente no convívio cultural dos gêneros secundários. Estes, por sua vez, têm uma íntima relação com a modalidade escrita da língua e se originam dos gêneros primários que, nesse processo, são reelaborados.

Com relação aos índices de totalidade dos gêneros do discurso, nos são apresentados três elementos: estilo, conteúdo temático e configuração composicional. $\mathrm{O}$ estilo, nesta perspectiva, não está relacionado ao estilo individual dos sujeitos, mas aos estilos de linguagem ou funcionais que se caracterizam como estilos de gênero. $\mathrm{O}$ conteúdo temático, por sua vez, é tomado como o que é dizível por meio dos gêneros, isto é, o objeto e a finalidade discursivos, bem como sua orientação de sentido para com os sujeitos interactantes, e a configuração composicional se refere à forma e à organização arquitetônica desse conteúdo: os tipos de construção do conjunto, o seu acabamento, a relação do autor com seu interlocutor etc.

Em nosso entendimento, tratar de leitura é tratar de textos pertencentes a diversos gêneros que circulam socialmente, instituindo a interação entre autores e leitores sócio-historicamente constituídos.

Nessa perspectiva, o ensino e a aprendizagem de leitura, nas instituições formais de ensino, devem ter como objeto o texto no gênero, tal qual propõe Geraldi (1997 [1991]), entre outros estudiosos da área. Essa abordagem, em tese, modifica o quadro tradicional de ensino e de aprendizagem: passa-se a não trabalhar mais com excertos de textos, desvinculados de seus suportes reais, o que deriva da compreensão de que textos não existem por si sós, mas materializados nos diversos gêneros discursivos. 


\section{Letrame nto(s)}

Nesta seção discutiremos o conceito de letramento, apresentando os dois modelos de letramento amplamente mencionados pela literatura da área, tanto quanto discutindo o que sejam práticas e eventos de letramento. Abordaremos, ainda, os conceitos de letramentos vernaculares e dominantes, dialogando acerca do trabalho em sala de aula envolvendo os usos sociais da modalidade escrita da língua.

Letramento: fenômeno vinculado aos contextos da vida humana

Letramento, neste artigo, é entendido como usos sociais da escrita, histórica e culturalmente situados. Conforme afirma Kleiman (1995, p. 19), "Podemos definir hoje o letramento como um conjunto de práticas sociais que usam a escrita, como sistema simbólico e como tecnologia, em contextos específicos, para objetivos específicos." Nessa perspectiva a escrita é tomada sob uma abordagem social, vinculada a seu contexto de produção e recepção, o que converge em grande medida com os princípios bakhtinianos sobre os usos da linguagem ${ }^{2}$.

Sob essa ótica, a escrita não pode ser concebida individualmente, numa perspectiva internalista, como têm se comportado historicamente muitas escolas. Ao invés disso, a modalidade escrita é vinculada ao contexto em que é utilizada, estando ambos (língua e contexto), junto a outros elementos, implicados no processo de construção de sentidos. Street (1984) explica que é o contexto que determina os diferentes usos e as funções da modalidade escrita da língua.

Nesse sentido, Barton (1994) define o letramento como ecologia da escrita. Tal metáfora justifica-se pelo fato de o letramento ser concebido dentro de um quadro em que se integra o contexto, ou seja, estuda-se a relação dos sujeitos com seu meio ambiente $^{3}$. Nesse caso, o letramento é parte do meio ambiente, exercendo influência sobre ele e, ao mesmo tempo, sendo influenciado pelo contexto.

Street (1984), por sua vez, explica que, uma vez relacionados ao contexto, e sendo esse um produto da ideologia de uma sociedade, os usos sociais da escrita são,

\footnotetext{
${ }^{2}$ Em nosso entendimento, os estudos do letramento vinculam-se a uma perspectiva mais efetivamente antropológica, enquanto o ideário bakhtiniano vincula-se a uma perspectiva mais efetivamente filosófica, mas compreendemos haver significativas aproximações entre ambos, o que tributamos a uma base epistemológica comum de natureza histórico-cultural.

${ }_{3}^{3}$ Co mpreendemos o conceito de ambiente, como assim o é nesse ideário, estendendo-se ao meio cultural e social.
} 
necessariamente, ideológicos. Assim, as práticas de letramento estão presas à ideologia, o que se reflete nos diferentes eventos de letramento pelos quais passam os sujeitos. Nessa perspectiva, compreender o significado de letramento na vida dos indivíduos é crucial para o entendimento acerca da forma pela qual utilizamos a escrita em nosso dia a dia e para as representações que construímos sobre ela.

Como as práticas sociais que se valem da modalidade escrita da língua são inúmeras e estão presentes em diversas esferas da atividade humana, podemos afirmar que existem diferentes letramentos, específicos de cada uma das esferas sociais. Entendemos letramento no plural devido ao fato de que essas interações humanas mediadas pela escrita possuem objetivos específicos estreitamente relacionados a seus contextos imediatos, o que as faz diferir substancialmente umas das outras.

Importa registrar, ainda aqui, que letramento, a nosso ver, não é sinônimo de alfabetização. Entendemos que a alfabetização é conteúdo - no sentido de estar contida em - do letramento, pois ela é constitutiva de uma das manifestações do fenômeno do letramento: a escolar (GONÇALVES, 2011). Enquanto a alfabetização está para a aquisição e para o manejo do código alfabético em contextos de sentido, o letramento está para os usos sociais da escrita em uma perspectiva antropológica mais ampla.

Street (1984), apontando para o fato de que há duas maneiras distintas de conceber e usar a escrita na sociedade, postula dois modelos de letramento: o primeiro é denominado modelo autônomo, e o segundo, modelo ideológico.

O modelo autônomo de letramento - prevalente na sociedade - caracteriza o uso da escrita desvinculado de seu contexto de produção, isto é, a escrita é "autônoma" em si mesma, e as remissões ao usuário da escrita implicam concepções de um sujeito abstraído de sua corporeidade e de sua historicidade. Nesse modelo, a escrita é tomada como tecnologia, e a compreensão textual é determinada apenas pelo funcionamento lógico interno do texto.

A modalidade escrita, sob essa lógica, é considerada superior à modalidade oral - havendo, portanto, uma dicotomização entre oralidade e escrita -, uma vez que a modalidade escrita da língua facultaria aos indivíduos o desenvolvimento cognitivo no que tange à abstração do real.

Nessa linha de reflexão, é função da escola trabalhar com tal abstração, isto é, o desenvolvimento da capacidade de abstrair é compreendido como elemento vinculado à escolarização, caracterizando, dessa forma, como "modernas" e/ou possuidoras de pensamentos científicos as sociedades escolarizadas, enquanto povos não escolarizados 
são concebidos como "primitivos" e/ou despossuidores de pensamento científico. Contra-argumentando, Street (1984, p. 26) explica que estudos antropológicos “[...] suggest that there is scientific and non-scientific thought in all societies and within all individuals."

Street (1984, p. 31) ainda assinala que todos os grupos sociais compartilham capacidades cognitivas comuns e conclui, portanto, que o uso da linguagem, tanto oral quanto escrita, envolve seleção, abstração e categorização por meio de critérios específicos.

O modelo ideológico de letramento, por sua vez, caracteriza as práticas de letramento como determinadas cultural e socialmente, isto é, considera sua dimensão heterogênea e plural. Nesse modelo, as práticas discursivas são gestadas pelos co ntextos de produção e recepção.

Street (1984) denomina o modelo alternativo de letramento ideológico a fim de destacar o fato de que não somente a cultura, mas também as estrututras de poder em uma sociedade são refletidas nas diferentes e inúmeras práticas de letramento. Segundo Street (2003, p. 8), o modelo ideológico de letramento, por levar em conta o contexto e não se centrar na autonomia da modalidade escrita da língua, parte da premissa de que práticas de letramento variáveis são enraizadas em relações de poder, "e que as aparentes inocência e neutralidade das "regras" atuam para disfarçar as maneiras de manter esse poder através do letramento."

Conceitos axiais nessa teoria são aqueles relacionados aos valores e aos usos atribuídos à escrita pelos diferentes povos, o que nos remete à discussão sobre práticas de letramento e eventos de letramento.

Práticas e eventos de letramento

As práticas de letramento são entendidas como valores e vivências internalizadas nos sujeitos relacionadas ao uso social da escrita.

Segundo Barton e Hamilton (2000), as práticas são moldadas por regras sociais e, acrescentamos, ideológicas e de poder. Elas constituem a base dos chamados eventos de letramento, que são concebidos como interações humanas instituídas pela modalidade escrita da língua. Os eventos de letramento, ao contrário das práticas, são

\footnotetext{
${ }^{4}$ [...] sugerem que há pensamentos científicos e não-científicos em todas as sociedades e entre todos os indivíduos. (tradução nossa)
} 
observáveis e até fotografáveis (HAMILTON, 2000). Eles surgem a partir das práticas de letramento e por elas são moldados. Enquanto os eventos de letramento constituem situações em que a escrita está presente e tem finalidade interacional, “[....] as práticas de letramento se referem a um conceito cultural mais amplo das formas específicas de pensar e de fazer a leitura e a escrita dentro dos contextos culturais" (STREET, 2003, p. $8)$.

Para que os eventos sejam entendidos faz-se necessária a compreensão das práticas subjacentes a eles. Hamilton (2000) utiliza a metáfora do iceberg para fazer a distinção entre eventos e práticas de letramento. Segundo ela, as práticas são a base submersa do iceberg, inferidas por meio dos eventos, que, por sua vez, constituem a ponta do iceberg, sua parte visível. Enfatizemos a dimensão social das práticas e dos eventos de letramento apontando para o fato de que eles vão se modificando ao longo do tempo baseados em práticas e eventos anteriores. Conforme elucida Barton (1994), as práticas de letramento são transmitidas de geração em geração, conectando-se, portanto, ao mesmo tempo com o passado e com o futuro. Os eventos de letramento, assim, podem ter valores e significados distintos em comunidades diferentes.

Discutir leitura, nesta abordagem, é considerar que diferentes grupos culturais apresentam práticas distintas de letramento, ou seja, vivenciam a leitura de forma diferente.

Letramentos vernaculares e dominantes e sua hibridização na escola

Ao tratar de letramento, tratamos de letramentos (no plural). Sob esse ideário, há letramentos dominantes e letramentos vernaculares (STREET, 2003; ROJO, 2009). Os primeiros remetem a usos da escrita ligados à erudição, praticados em espaços mais formais e com relativa disseminação em nível global mais amplo. Os segundos são letramentos relacionados ao cotidiano, comprometidos com as representações de mundo de grupos sociais específicos e que são, muitas vezes, foco de discriminação, o que nos remete às relações de poder que subjazem aos estudos do letramento.

Segundo Kleiman (1995), nas escolas brasileiras ainda predomina o modelo autônomo de letramento que reproduz os letramentos dominantes e que objetiva promover atividades que visam ao desenvolvimento das capacidades universalistas de interpretar e escrever textos abstratos, concentradas nos processos intrassubjetivos. Quando tal desenvolvimento não acontece, o fracasso e a sua responsabilidade são 
atribuídos ao indivíduo, que tende a pertencer a grupos social e economicamente marginalizados que se embatem em relações de poder nas sociedades tecnológicas (KLEIMAN, 1995).

Concordamos com afirmações de Street (2003, p. 1) de que o professor, nesse contexto, tem de ter a sensibilidade de conhecer as práticas de letramento de seus alunos, isto é, os letramentos vernaculares, para poder trabalhar com elas (sem negá-las e marginalizá-las) e para poder instituir outras e novas práticas de letramento, principalmente aquelas relacionadas aos letramentos dominantes.

Assim, tem de haver uma preocupação com a transformação social: professores têm de estar engajados para que seus alunos ampliem suas práticas de letramento no que diz respeito à leitura, lendo textos em diversos gêneros discursivos que instituem relações intersubjetivas em diferentes esferas da atividade humana e se relacionam ao letramento dominante. É a hibridização entre tais letramentos, entre vivências social e historicamente situadas com a escrita que representa o foco do trabalho escolar.

\section{PROCEDIMENTOS METODOLÓGICOS}

Compreendemos que ações didáticas delineiam-se a partir de concepções docentes. Nesse sentido, nossa pesquisa busca compreender o que professores de Língua Portuguesa dos anos finais do Ensino Fundamental de escolas estaduais de Florianópolis informam conhecer por teorias sobre gêneros discursivos e sobre letramento e sua implicação no trabalho de formação de leitores.

\section{Descrevendo o estudo, os participantes e as diretrizes para análise}

O município de Florianópolis possui 29 escolas estaduais voltadas aos anos finais do Ensino Fundamental - foco de nosso estudo. Nelas havia, no ano letivo de 2011, 52 professores de Língua Portuguesa em atividade, os quais constituem os participantes desta pesquisa. Desse número total, 47 (o que corresponde a 90,4\% do quadro de docentes) aceitaram realizar entrevistas - nosso instrumento de geração de dados. Tal grupo de educadores é composto por profissionais efetivos e contratados temporariamente. Não contamos com professores do sexto ano de ensino, pois, com a 
implementação gradual dos nove anos de educação na rede ${ }^{5}$, em 2011 não houve o sexto ano (antiga quinta série).

As concepções docentes sobre leitura, especificamente suas concepções teóricas, foram depreendidas por meio de entrevista. As entrevistas foram realizadas individualmente e foram gravadas com permissão dos docentes. Durante o diálogo foram realizados diversos questionamentos acerca do ato de ler, no que diz respeito a quatro domínios distintos: domínio ontológico - entendido como a visão acerca da essência do ato de ler; domínio axiológico - aquele que remete aos valores sociais, culturais e históricos da leitura; domínio teórico-epistemológico - entendido como os princípios sobre os quais o ensino da leitura está fundamentado; e domínio metodológico - entendido como as bases procedimentais do ensino. Contudo, como este artigo constitui um recorte de pesquisa, enfocamos as concepções docentes em se tratando do domínio teórico-epistemológico.

Após a realização das entrevistas com os professores participantes, transcrevemos as falas e iniciamos o processo de interpretação e análise. Necessário registrar que não nos valemos de métodos analíticos da Análise da Conversação; valemo-nos de uma abordagem interpretativista (MASON, 1998) das enunciações desses professores.

Esta pesquisa constitui, portanto, um estudo de caso por ter como objetivo descrever e analisar concepções teóricas referentes ao ensino e à aprendizagem da leitura em se tratando de professores de Português dos anos finais do Ensino Fundamental da rede estadual de Florianópolis, isto é, buscamos entender se há reverberações do ideário histórico-cultural nas concepções docentes acerca do trabalho com leitura em sala de aula.

Com relação ao método de pesquisa, pode ser considerado de abordagem qualitativa (FLICK, 2004), ainda que tenhamos nos valido pontualmente de menções de natureza quantitativa em uma abordagem complementar (BAQUERO, 2009); de todo modo, o enfoque é prevalecentemente qualitativo.

\footnotetext{
${ }^{5}$ A Lei $\mathrm{n}^{\circ}$ 10.172, de 9 de janeiro de 2001, estabelece o Ensino Fundamental de nove anos. O objetivo dess a lei é assegurar a todas as crianças um te mpo mais longo de convívio escolar, maiores oportunidades de aprender e, com isso, criar espaço para uma aprendizagem com qualidade. Disponível no site http://www.sed.sc.gov.br. Aces so em 25 de julho de 2012.
} 


\section{ANÁLISE DOS DADOS}

Nesta seção analisaremos as respostas geradas quando indagou-se acerca do reconhecimento de teorias que tratam de gêneros discursivos e de letramento.

\section{Gêneros discursivos na ancoragem do processo de ensino da leitura}

A questão elaborada, na entrevista, a respeito das teorias sobre gêneros do discurso é a seguinte: $O$ que você conhece sobre as teorias de gêneros discursivos? E quais as implicações pedagógicas que vê no processo de ensino e aprendizagem da leitura? Atentemos para a Tabela 1 a seguir:

Tabela 1

\begin{tabular}{c|c|c}
\hline Reconhecimento & Quantidade & \% \\
\hline Reconhecem & 36 & 76,6 \\
\hline Não reconhecem & 11 & 23,4 \\
\hline TOTAL & $\mathbf{4 7}$ & $\mathbf{1 0 0 , 0}$ \\
\hline
\end{tabular}

Título: Teorias sobre gêneros discursivos Fonte: Construção nossa

Vemos que um número expressivo - 76,6\% - dentre os participantes informam conhecer as teorias sobre gêneros discursivos, enquanto $23,4 \%$ afirmam não conhecêlas. Vejamos algumas respostas destes últimos participantes de pesquisa: (1) Não conheço. (COM, entrevista em 15/09/2011); (2) Não. (RAM, entrevista em 31/08/2011); (3) Não. (SCMA, entrevista em 29/08/2011); (4) Não. (BMC, entrevista em 21/09/2011); (5) Teoria? Como assim? Não. (DMIJ, entrevista em 29/08/2011); (6) Conheço os didáticos [os textos em gêneros veiculados nos livros didáticos]. (HFS, entrevista em 22/09/2011); (7) Já ouvi falar, mas não procuro pesquisar sobre o assunto. (RFB, entrevista em 15/09/2011).

A partir de excertos com esse conteúdo, concluímos que as discussões linguísticas a respeito de gêneros e, consequentemente, do ensino operacional e reflexivo da língua (GERALDI, 1997 [1991]), cujo objeto passa a ser o texto em gênero do discurso (BAKHTIN, 2010 [1952/53]), ainda não fazem parte das representações dos participantes desta pesquisa. As enunciações em (1) a (5) ilustram o não contato com o conceito gêneros discursivos, bem como com teorias implicadas nesse conceito; os excertos (6) e (7), por outro lado, sugerem a não apropriação desse conhecimento, mas a 
existência de um contato inicial dos docentes com o conceito em questão. O conteúdo em (6) suscita conhecimento dos gêneros didáticos, is to é, textos em gêneros presentes nas unidades dos livros utilizados nas escolas. Já o conteúdo em (7) sugere conhecimento superficial, mas não estudo do assunto.

Diante de um quadro como esse, amplia-se, a nosso ver, a importância de oferta de cursos de formação continuada, por meio dos quais seria possível uma apropriação de implicações do ideário histórico-cultural por parte de um maior número de professores de Língua Portuguesa em exercício. Interessante observar, somado a isso, que muitos dentre os docentes que responderam conhecer as teorias sobre gêneros, quando indagados sobre o que de fato conhecem e como tais teorias podem ajudar na formação de leitores, hesitaram em responder ou tergiversaram para outros focos, o que sugere, a nosso ver, não apropriação efetiva desse ideário.

Observemos, então, respostas de professores que informam conhecer tais teorias: (8) Conheço. Ela ajuda a pessoa a perceber...; hoje em dia tem tantos meios de comunicação. Cada produção é um gênero. (LWA, entrevista em 14/09/2011); (9) Conheço, posso trazer atividades diferenciadas e bem demarcadas e trabalhar os conceitos de uma maneira mais prática, por exemplo: narração, como é a estrutura; uma carta, como é a estrutura. (FLV, entre vista em 14/09/2011); (10) Conheço, ajuda o aluno a conhecer estrutura. (RFS, entrevista em 13/09/2011); (11) Elas contribuem porque separam as possibilidades de se manifestar uma ideia, de diferentes maneiras. (GMCJ, entrevista em 07/09/2011); (12) É mais um conhecimento para o professor, para encaminhar os conteúdos. (BCLV, entrevista em 06/09/2011). Pelas respostas (8) a (12) depreendemos que os professores informam conhecer teorias sobre gêneros, contudo se trata de enunciações genéricas que não focalizam especificidades desse conceito, a exemplo da compreensão fundante de que os gêneros do discurso instituem relações humanas nas diferentes esferas sociais e que tais gêneros são materializados na forma de enunciados, os quais constituem elos da comunicação discursiva (BAKHTIN (2010 [1952/53]), e que, portanto, o objetivo nas aulas de língua materna não é tomar os gêneros como objeto ontológico de ensino e aprendizagem, mas tornar compreensível que tratar de língua e de leitura é, indubitavelmente, tratar de gêneros.

Inferimos a não apropriação do ideário, também, em respostas que relacionam o trabalho com gêneros à estruturação textual, conforme podemos observar nas falas (9) e (10), além de interpenetrações entre gêneros do discurso e tipologias textuais. No excerto (9), consta narração como um gênero discursivo, em mais um exemplo dessas 
interpenetrações. Sobre isso, escreve Brait (2001, p. 3): “[...] não podemos confundir tipologias textuais [...] com gêneros discursivos. Se acreditamos em pecado mortal, essa confusão é o melhor exemplo." Cremos que esse equívoco ocorre por não haver, de fato, apropriação desse saber por parte de muitos professores; ao que parece e, conforme discute Batista (2003), muitos docentes baseiam suas ações em livros didáticos que têm a função de estruturar as aulas de Português e, por não disporem de tempo para participarem de cursos de atualização profissional, esses docentes tendem a se fixar em tais livros. A consequência disso é a transposição [para]didática de que tratam Halté (2008 [1998]) e Petitjean (2008 [1998]): nesses casos, como mostra Cerutti-Rizzatti (2012), os professores transpõem o conteúdo do livro para suas aulas. Comportamentos dessa natureza talvez justifiquem a interpenetração entre gêneros discursivos e tipologias textuais. De acordo com Brait (2000), os próprios Parâmetros Curriculares Nacionais contribuem para essa compreensão enviesada.

Em (8) consta a associação entre produção e gêneros, do que depreendemos duas possibilidades de interpretação: a) uma compreensão mais vinculada aos eixos desse recorte teórico, possivelmente o entendimento acerca da impossibilidade de empreender quaisquer usos da língua fora dos gêneros discursivos, tal qual prevê Bakhtin (2010 [1952/53]); ou, por outro lado: b) a percepção de uma associação circunscrita a gêneros discursivos e produção textual especificamente, universo do qual os processos de leitura e escuta estariam à margem. Uma interpretação tal qual em $b$ parece-nos possível se considerarmos o que entendemos ser uma ênfase expressiva na produção textual, em se tratando das discussões sobre gêneros discursivos, derivada de desdobramentos do chamado Sociointeracionismo discursivo, como se apresenta no conceito de sequências didáticas, em Dolz, Noverraz e Schneuwly (2004), focado substancialmente no ato de produzir textos.

O conceito de sequências didáticas aparece na enunciação de outros docentes, como em: (13) Eu trabalho com sequência didática, nessa sequência já estão inseridos os gêneros. Ali a gente vai trabalhando tudo. O aluno vai sabendo usar o gênero. Essa ideia de trabalhar com sequência veio do Gestar. (LSM, entrevista em 01/09/2011); (14) Ajudam totalmente. Tem uma sequência de gêneros a ser trabalhada. (VRA, entrevista em 30/08/2011). Nesses excertos, observamos menção a teorizações acerca dos gêneros advindas de cursos de formação profissional continuada; nesse caso, reiteramos, com enfoque no conceito de sequências didáticas. Em se tratando desse 
conceito, parece-nos claro, tal qual em Dolz, Noverraz e Schneuwly (2004, p. 97), seguir o enfoque do estudo dos gêneros na produção textual:

\footnotetext{
Uma "sequência didática" é um conjunto de atividades escolares organizadas, de maneira sistemática, em torno de um gênero textual oral ou escrito. [...] Uma sequência didática tem, precisamente, a finalidade de ajudar o aluno a dominar melhor um gênero de texto, permitindo-lhe, assim, escrever ou falar de uma maneira mais adequada numa dada situação de comunicação.
}

Em nossa compreensão, na metodologia das sequências didáticas (DOLZ; NOVERRAZ; SCHNEUWLY, 2004) dá-se o que Geraldi (2010) chama de tornar ontológico o que é processual, uma vez que "[...] os gêneros podem ser agrupados em função de um certo número de regularidades linguísticas e de transferências possíveis" (DOLZ; NOVERRAZ; SCHNEUWLY, 2004, p. 120). Por meio de uma apresentação inicial de um gênero, seguida de consecutivos módulos em que são trabalhadas as dificuldades dos alunos e as características do determinado gênero, chega-se à produção final, momento caracterizado pela expectativa de que os alunos tenham se tornado proficientes na produção do gênero em questão. Na perspectiva da elaboração didática a partir do conceito bakhtiniano de gêneros discursivos, entendemos estes tomados como práticas de uso da língua, na dimensão processual e não ontológica do conceito. Como essas práticas de uso linguístico não são fixadas, não há como listá-las aprioristicamente, assinala Geraldi (2010). Tratar o gênero discursivo em uma perspectiva ontológica é destituí-lo de sua natureza processual, conferindo-lhe uma condição de artefato passível de esquadrinhamento e controle escolar. Essa é uma questão delicada que seguramente demanda novas reflexões.

Ainda em se tratando da ancoragem da aula de leitura em teorias sobre gêneros discursivos, outras respostas, ao que parece, aproximam-se mais diretamente do enfoque histórico-cultural na perspectiva com que vimos lidando neste estudo. Vejamos: (15) Eu vi as teorias de Bakhtin, Vigotski. Eu acho que é fundamental. A teoria te abre um leque de conhecimento, um horizonte de opções. (FMM, entrevista em 29/08/2011); (16) Sim, eu trabalhei bastante na faculdade com gêneros e na sala eu não focalizo só um gênero, é variado: poesia, contos... (BFL, entrevista em 12/08/2011). Ainda:

(17) Sim, a gente fez o Gestar e na faculdade a gente teve num semestre, então para mim é muito claro. Só de o professor ter noção dessa teoria...; mas eles não prestam atenção se eu estou falando em gênero ou tipo. Eu acho que os outros professores deveriam saber essa diferença. Isso dificulta. (PK, entrevis ta em 20/09/2011). 
Por tais excertos, visualizamos concepções sobre gêneros mais próximas aos postulados que são discutidos na Linguística. No excerto (15) há menção a Bakhtin e Vigotski, em um entendimento segundo o qual a teoria faculta ao docente organização da ação pedagógica. Já em (16), o participante de pesquisa aponta a diversidade de gêneros que pode ser abordada nas aulas de Língua Portuguesa, e a fala em (17) ilustra o conhecimento de um professor que participa de curso de formação continuada, como o Gestar, e que, ao que parece, entende a diferenciação entre gêneros e tipos textuais. As reverberações do ideário histórico-cultural que entendemos haver nesses excertos de (15) a (17) constituem um número bastante reduzido em relação ao conjunto de representações docentes sobre o tema em questão.

Entendemos que os dados discutidos até aqui revelam a importância de uma ação acadêmica que objetive rever consequências do processo da formação inicial na habilitação em licenciatura, considerando ainda a necessidade de criar modos de aproximação da universidade com docentes que lecionam nas escolas da Educação Básica, a fim de promover ressignificações em suas concepções [dos educadores] para o trabalho com leitura e, mais abrangentemente, com língua.

\section{Letramento na ancoragem do processo de ensino da leitura}

Vejamos agora a organização interpretativa das respostas quando o questionamento feito versou sobre teorias de letramento. A pergunta feita é semelhante à dos gêneros, modificada, obviamente, a teoria em foco. Observemos a Tabela 2:

Tabela 2

\begin{tabular}{c|c|c}
\hline Reconhecimento & Quantidade & \% \\
\hline Não reconhecem & 30 & 63,8 \\
\hline Reconhecem & 17 & 36,2 \\
\hline TOTAL & $\mathbf{4 7}$ & $\mathbf{1 0 0 , 0}$ \\
\hline
\end{tabular}

Título: Teorias sobre letramento

Fonte: Construção nossa

De acordo com a Tabela 2, grande parte dos professores entrevistados - 63,8\%não reconhece teorias sobre letramento, como podemos observar em algumas respostas: (18) Não conheço. (CPM, entrevista em 15/09/2011); (19) Não conheço, não tive na minha formação, mas agora estou começando a me interessar e a buscar leituras. (FLV, entrevista em 14/09/2011); (20) Não, não vi. (QGA, entrevista em 02/09/2011); (21) Que eu me lembre, não. (MRSM, entrevista em 24/08/2011); (22) Não conheço. 
(BPM, entrevista em 23/08/2011); (23) Não vi ainda. (JS, entrevista em 12/08/2011); (24) Se não estou enganado, Cagliari fala alguma coisa das teorias de letramento, de como trabalhar questões para criança ouvir, a oralidade, leitura... Não sei se é isso também. (RCS, entrevista em 09/08/2011); (25) Se eu vi já faz um tempo. (HSR, entrevista em 09/08/2011). Com base nesses excertos e em outros tantos de conteúdo similar, depreendemos que a maior parte dos professores participantes ainda não teve contato com teorias que tratam dos usos sociais da escrita, nem em seus cursos de graduação, tampouco em cursos de formação continuada. Kleiman (1995) explica que os estudos sobre letramento são recentes no Brasil, chegando aqui no final do século XX. Segundo a autora, tais estudos estão em uma fase vigorosa e incipiente, configurando-se atualmente como uma das vertentes de pesquisa que mais bem une interesse teórico a interesse social.

Ao que parece, os estudos voltados à questão do letramento estão ainda ganhando território no âmbito acadêmico brasileiro, tornando-se área de pesquisa fértil para o entendimento de problemas linguísticos socialmente relevantes, entretanto parece incipiente o ensino de implicações dessa teoria nos cursos de Letras, entendimento esse corroborado nos excertos em questão: a maioria dos docentes informa não ter entrado em contato com esse ideário em seus cursos de graduação, e grande parte deles $-83,7 \%$ - concluiu sua licenciatura após os anos $1990^{6}$. Como os estudos do letramento estão "ganhando corpo" nas universidades há pouco tempo, entendemos a não abordagem dessas teorias em diferentes cursos de formação continuada, além de considerarmos o tempo que as discussões teóricas demandam para chegar à esfera escolar, tal qual mostra Gonçalves (2011).

A nosso ver, entretanto, atualmente não há como não levar a termo tal discussão nas licenciaturas em nosso país, assim como nos cursos de formação continuada. Em vista da nova configuração social e econômica contemporânea, bem como da consideração de que vivemos em uma cultura heterogênea, é mister que os professores de Português compreendam os significados do letramento a fim de que possam entender a forma pela qual seus alunos utilizam a escrita cotidianamente e as representações que cons troem sobre ela, de modo a ressignificar a ação docente.

\footnotetext{
${ }^{6}$ Antes de conversarmos com os professores acerca de suas concepções teóricas sobre o ensino e a aprendizagem de leitura, fizemos perguntas direcionadas a seu perfil a fim de que pudéssemos compreender quem são tais docentes.
} 
Outros professores, por sua vez, informam conhecer postulados acerca do letramento. Atentemos para respostas representativas desse comportamento: (26) De vez em quando estou lendo sobre isso, porque algumas criancinhas vão para a minha sala. Hoje letramento é o que lê, escreve e compreende, e antigamente a gente chamava de alfabetização. (PK, entrevista em 20/09/2011); (27) Conheço. Temos bastante isso nas séries iniciais. Ajuda, mas limita, dá um certo entrave no aluno quando ele chega no Fundamental 2. (MAES, entrevista em 09/09/2011, ênfase nossa); (28) Conheço muito vagamente. Até porque isso é mais das séries iniciais. (GMCJ, entrevista em 07/09/2011); (29) Vi sim. Magda Soares. Eu acho que é mais para séries iniciais. (VRA, entrevista em 30/08/2011).

Inferimos, por essas respostas, que os professores que informam conhecer teorias sobre letramento o fazem em uma associação ligada ao universo dos anos iniciais do Ensino Fundamental, o que sugere uma compreensão de letramento muito relacionada à alfabetização. Essa acepção possivelmente decorre da historicidade do termo: tradicionalmente os conceitos vêm sendo tratados como sinônimos. Entendemos alfabetização como conteúdo do letramento, visto que é parte substancial do letramento chamado escolar (GONÇALVES, 2011). Nessa perspectiva, a alfabetização diz respeito ao aprendizado e ao manejo do código alfabético em contextos de sentido, enquanto o letramento se refere aos usos sociais da escrita em uma perspectiva antropológica mais ampla. O que ocorre, assinala Kleiman (1995), é que as escolas brasileiras tendem, nas séries iniciais, a se preocupar unicamente com a aprendizagem da decodificação em detrimento da observância dos contextos de produção e recepção de texto, de seu uso social, a gosto do modelo autônomo de letramento (STREET, 1984).

Entendemos que a natureza difusa das percepções sobre o fenômeno do letramento que depreendemos na maior parte das respostas justifica, em boa medida, a compreensão de letramento como limitador, conforme ilustra a enunciação (27). Possivelmente está implicado nessa percepção o olhar do letramento associado à erudição, o que tornaria o ingresso no processo de escolarização mais difícil para alguns segmentos sociais. Compreensões como essa nos levam a Heath (2001 [1982]), etnógrafa que materializa em seu estudo as implicações de uma ação escolar comprometida com o modelo autônomo de letramento, muito próximo de práticas de letramento de alguns grupos sociais e, por outro lado, muito distante de práticas de 
letramento de outros grupos. De todo modo, em (27), parece prevalecer um olhar ainda bastante focado nas premissas do modelo autônomo de letramento.

Uma compreensão efetiva dos desdobramentos do fenômeno do letramento, em nossa compreensão, contribuiria para que os processos de ensino e aprendizagem ganhassem novos contornos, dada a possibilidade de maior atenção aos motivos para que determinadas práticas discursivas escritas sejam potencializadas. Uma ação pedagógica marcada pela sensibilidade antropológica à ecologia dos usos da escrita (BARTON, 1994) parece fundamental para que o aluno retome seu papel de sujeito ativo historicamente situado no processo de coconstrução de sentidos, reconhecendo-se em uma ação pedagógica pautada na hibridização entre letramentos vernaculares e letramentos dominantes, sem ter de assumir como verdade absoluta o que o professor autoridade - enuncia. Trata-se, aqui, de pleitear a horizontalização das vivências com a escrita, tal qual propõem Kalantzis e Cope (2006) e não a substituição das experiências dos alunos, movimento esse que parece estar subjacente a uma compreensão do letramento como limitador.

Compreensões com desdobramentos como os discutidos no parágrafo anterior parecem presentes também em: (30) Já ouvi falar. Quem trabalha mais o letramento é uma professora que pega os alunos mais defasados e trabalha com eles. É uma professora de apoio. Letramento eu sei que ela trabalha. Precisa trabalhar. (HFS, entrevista em 22/09/2011). Nesse excerto surge, mais uma vez, a força do modelo autônomo, a vinculação do letramento ao conhecimento escolarizado associado à faixa etária apenas, independentemente de inserção sociocultural e econômica. Somente sob uma perspectiva dessa natureza se justifica o discurso da compensação de lacunas; seguramente o fenômeno do letramento surgiu de uma proposição diametralmente oposta a essa.

Ainda outros excertos em se tratando do conhecimento de teorias sobre letramento: (31) Já ouvi falar, mas não uso. Ela ajuda, mas eu não me prendo muito ao letramento. (RIP, entrevista em 20/09/2011); (32) Conheço um pouquinho. (LWA, entrevista em 14/09/2011); (33) Conheço. Se o aluno entende, se tem letramento, ele vai conseguir produzir. (BCLV, entrevista em 06/09/2011). Em nossa compreensão, e à luz do ideário histórico-cultural, o trabalho com leitura tem como base as práticas de letramento dos alunos (STREET, 1988), a fim de que o professor de Língua Portuguesa possa conhecer o grupo com que trabalha, identificar suas necessidades e entender como se relacionam com a escrita cotidianamente. A sensibilidade a esses usos contribui para 
um trabalho com textos de diversos gêneros discursivos (BAKHTIN, 2010 [1952/53]) que vise à hibridização entre letramentos vernaculares e letramentos dominantes (STREET, 2003), no intuito de potencializar práticas de uso da língua de modo a facultar aos alunos inserção em diferentes esferas de atividade humana.

As aulas de leitura, assim, configurariam espaços em que se leva em consideração não apenas aspectos cognitivos, mas aspectos vinculados à interação, ao contexto, os quais demandam atividades cognitivas de uma natureza ou de outra. Tratase de conceber a leitura como uma ação vinculada às práticas de letramento, as quais se distinguem entre os inúmeros grupos culturais e se transformam ao longo do tempo, ampliando, assim, os eventos de letramento dos quais participam os sujeitos. Com base em uma compreensão do letramento como uma relação entre texto e contexto (STREET, 1984), ou seja, como uma ecologia da escrita (BARTON, 1994), a ação pedagó gica pode significar para inúmeros grupos sociais.

\section{CONSIDERAÇÕES FINAIS}

Inferimos pela análise aqui apresentada que, apesar de a maioria - 76,6\% informar reconhecer teorias sobre gêneros, parece não ter havido ainda uma apropriação desse ideário: há professores que informam conhecer gêneros didáticos (aqueles veiculados nos livros didáticos); há outros que interpenetram conceitos distintos, tais como gêneros discursivos e tipologias textuais, tratando-os como sinônimos; e há outros ainda que informam trabalhar com gêneros, porém o que focalizam de fato é a estruturação textual.

Já com relação às teorias sobre letramento, a maioria dentre os participantes de pesquisa - 63,8\% - informa não conhecê-las, e aqueles poucos que afirmam ter conhecimento sobre o tema parecem vincular letramento à alfabetização, concebendo o fenômeno do letramento como de relevância para os anos iniciais.

O conteúdo da seção de análise dos dados sugere-nos, portanto, a importância de a academia rever sua ação em se tratando tanto da formação inicial, quanto de sua participação nos processos de formação continuada. Conceitos como gêneros discursivos e letramento parecem ainda muito difusos nas representações docentes e, à luz das bases do ideário histórico-cultural, afiguram-se hoje como conceitos capitais no trabalho com ensino e aprendizagem das práticas de leitura na escola. Trata-se de dois conceitos cuja apropriação teórica, em todos os desdobramentos que isso traz consigo, é 
de fundamental importância na esfera escolar. À universidade compete uma ação mais consequente nos processos de formação que empreende e um compromisso político mais efetivo com os resultados dessa mesma formação.

Retomando, enfim, nosso questionamento inicial: Em se tratando de como professores de Português dos anos finais do Ensino Fundamental de escolas estaduais de Florianópolis/SC, informam trabalhar com leitura - com foco em sua ancoragem teórica -, é possível depreender fundamentos do ideário históricocultural, nos contornos com que esse ideário tem se estabelecido nas discussões teóricas e nos documentos oficiais no Brasil?, depreendemos ecos desse ideário nas concepções aqui analisadas, mas de maneira ainda muito incipiente, o que sugere reiteramos - a importância e a urgência de a academia rever suas ações nas formações iniciale continuada de docentes.

\section{REFERÊNCIAS}

Bakhtin, M. (2010) [1952/53]. Os gêneros do discurso. In: Estética da criação verbal. $5^{\text {a }}$ edição - São Paulo: Editora WMF Martins Fontes, p. 261-306.

Paulo: Hucitec. (2009) [1929]. Marxismo e filosofia da linguagem. 13 $3^{\mathrm{a}}$ edição - São

Baquero, M. (2009). A pesquisa quantitativa nas Ciências Sociais. Porto Alegre: Editora da UFRGS.

Barton, D. (1994). The social basis of literacy. In: Literacy: an introduction to the ecology of written language. Cambridge/USA: Brackwell, p. 33-52.

Batista, A. A. G. (2003). Livro didático de língua portuguesa, letramento e cultura da escrita. Campinas, SP: Mercado de Letras.

Brait, B. (2001). Leituras: formas vivas de surpreender significações. In: V. A. Aguilera \& L. Límoli (Orgs.) Entrelinhas e entretelas: os desafios da leitura. Londrina, p.1-20.

(2000).PCNs, gêneros e ensino de língua: faces discursivas da textualidade. In: R. Rojo (org.). A prática de linguagem em sala de aula: praticando os PCNs. Campinas, SP: Mercado de Letras, p. 15-26.

BRASIL. Instituto Nacional de Estudos e Pesquisas Educacionais Anísio Teixeira INEP. PISA 2009.

Catoia Dias, S. (2012). O ato de ler e a sala de aula: concepções docentes acerca do processo de ensino e de aprendizagem de leitura/práticas de leitura. Dissertação de Mestrado pelo Programa de Pós- graduação em Linguística da Universidade Federal de Santa Catarina. Florianópolis. 
Cerutti-Rizzatti, M. E. (2012). Ensino de Língua Portuguesa e inquietações teóricometodológicas:os gêneros discursivos na aula de português e a aula (de português) como gênero discursivo. São Paulo: Revista Alfa.

Cope, B. \& Kalantizis, M. (2006). Multiliteracies. London and NY: Routled ge.

Dolz, J., Noverraz, M. \& Schneuwly, B. (2004). Sequências didáticas para o oral e a escrita: apresentação de um procedimento. In: Campinas, SP: Mercado de Letras, p. 95-128. Gêneros orais e escritos na escola.

Faraco, C. A. (2007). O estatuto da análise e interpretação dos textos no quadro do Círculo de Bakhtin. In: A. M. M. Guimarães, A. R. Machado \& A. Coutinho (Orgs.) $O$ interacionismo Sociodiscursivo: questões epistemológicas e metodológicas. 1. ed. Campinas: Mercado de Letras, 2007. p. 43-50.

Flick, U. (2004). Uma introdução à pesquisa qualitativa. Trad. Sandra Netz. - 2 ed. Porto Alegre: Bookman.

Fischer, S. R. (2006). Lendo o futuro. In: História da leitura. São Paulo: Editora UNESP, p. 279-315.

Geraldi, J. W. (2010). A aula como acontecimento. São Carlos: Pedro \& João Editores.

Fontes. (1997) [1991]. Portos de passagem. 4 $4^{\text {a }}$ edição. São Paulo: Martins

Gonçalves, F. C. (2011). Alfabetização sob o olhar dos alfabetizadores: um estudo sobre essencialidades, valorações, fundamentos e ações no ensino da escrita na escola. Dissertação de Mestrado pelo Programa de Pós-graduação em Linguística da Universidade Federal de Santa Catarina. Florianópolis.

Halté, J-F. (2008) [1998]. O espaço didático e a transposição. In: Fórum Linguístico, Florianópolis, p. 117-139, jul./dez.

Hamilton, M. (2000). Expanding the new literacy studies. In: D. Barton, M. Hamilton \& R. Ivanic, Situated literacies. London: Routledge, pp. 16-34.

Heath, S. B. (2001) [1982]. What no bedtime story means: narrative skills at home and school. In: A. Duranti (Org.) Linguistic Anthropology: a reader. Oxford: Blackwel, pp. 318-342

INAF BRASIL 2009 - Principais Resultados. Disponível em: $<$ http://www.ipm.org.br/download/inaf_brasil2009_relatorio_divulgacao_final.pdf $>$. Acesso em: 08 fev. 2010.

Kleiman, A. B. (1995). Modelos de letramento e as práticas de alfabetização na escola. In:___org.) Os significados do letramento: Uma nova perspectiva sobre a prática social da escrita. Campinas, SP: Mercado de Letras, pp. 15-61. 
Mason, J. (1998). Qualitative researching. London: S AGE Publications.

Petitjean, A. (2008) [1998]. Importância e limites da noção de transposição didática para o ensino do francês. In: Fórum Linguístico, Florianópolis, p. 83-116, jul/dez.

Rodrigues, R. H. (2005). Os gêneros do discurso na perspectiva dialó gica da linguagem: a abordagem do Círculo de Bakhtin. In: J. L. Meurer, A. Bonini \& D. Motta-Roth, (Orgs.). Gêneros: teorias, métodos, debates. São Paulo: Parábola, pp. 152-183.

Rojo, R. (2009). Letramentos múltiplos, escola e inclusão social. São Paulo: Parábola Editorial.

Schneuwly, B. (2004). Gêneros e tipos de discurso: considerações psicológicas e ontogenéticas. In: ; J. Dolz, Gêneros orais e escritos na escola. Campinas/SP: Mercado das Letras, pp. 21- 40.

Street, B. (1984). The 'autonomous' model: literacy and rationality. In: Literacy in theory and practice. Cambridge: CUP, pp.19-43.

(1984). The 'ideological' model. In: . Literacy in theory and practice. Cambridge: CUP, pp. 95-125.

(1984). The 'autonomous' model: literacy and rationality. In: Literacy in theory and practice. Cambridge: CUP, pp. $19-43$

(1988). Literacy practices and literacy myths. In: R. Saljo (Org.) The written world: studies in literacy thought and action. Nova Iorque: Springer-Verlag.

(2000). Literacy events and literacy practices: theory and practice in the New Literacy Studies. In: M. Martin-Jones \& K. Jones, Multilingual literacies: reading and writing different worlds. John Benjamins B. V., pp. 17-29.

(2003). Abordagens alternativas ao letramento e ao desenvolvimento. Teleconferência Unesco - Brasil - sobre letramento e diversidade. [s.1.], outubro de 2003.

(2010). Os novos estudos sobre o letramento: histórico e perspectivas. In: M. Marinho (Org.). Cultura escrita e letramento. Belo Horizonte: Editora UFMG, pp. 3353.

\section{A AUTORA}

Sabatha Catoia Dias possui licenciatura e bacharelado em Letras - Língua Portuguesa e mestrado em Linguística pela Universidade Federal de Santa Catarina (UFSC). Tem experiência com docência nos anos finais do Ensino Fundamental e com tutoria no ensino a distância $(\mathrm{EaD})$. Atualmente, é doutoranda no Programa de Pós-Graduação em Linguística da UFSC e integra o Núcleo de Pesquisas em Linguística Aplicada (NELA). Seu objeto de pesquisa é leitura, com foco no processo de ensino e de aprendizagem na Educação Básica.

E-mails : sabathadias@gmail.com/sabathacd@ hotmail.com 